\title{
Modeling Climate Change and its Impacts on Food Barley (HorduemvulgareL.) Production using Different Climate Change Scenariosin Lemubilbilo District, Oromia Regional State,Ethiopia
}

\author{
BekeleKebebe $^{1 *}$, DiribaKorecha ${ }^{2}$, GirmaMamo $^{3}$, Tilahun Dandesa ${ }^{4}$, MekonnenYibrah $^{1}$ \\ ${ }^{I}$ National Meteorological Agency, Addis Ababa, Ethiopia \\ ${ }^{2}$ USAID-Fewsnet-Addis Ababa, Ethiopia \\ ${ }^{3}$ Ethiopian Institution of Agricultural Research, Addis Ababa, Ethiopia \\ ${ }^{4}$ Agricultural Transformation Agency, Addis Ababa, Ethiopia
}

*Corresponding Author: BekeleKebebe, National Meteorological Agency, Addis Ababa, Ethiopia

\begin{abstract}
Agriculture remains the main source of food and income for most rural communities in Ethiopia. Understanding the impact of climate change on crop production can help to optimize schemes and increase yields. The main aim of this study was, therefore, to modeling climate change and its impacts on food barley (horduem vulgare l.) production using different climate change scenarios in Lemu Bilbilo district, Oromia regional state, Ethiopia. Time series anomaly for temperature showed that both annual maximum and minimum temperature have increased by $0.06 \mathrm{oC}$ and $0.11 \mathrm{oC}$ respectively and rainfall showed slight variability during the period of 1980-2010.The projected temperature and rainfall pattern shows that an overall increasing trend in annual temperature and significant variation of monthly and seasonal rainfall from the historical period of time. Days to flowering, maturity and yield of HB1307 variety simulated by DSSAT V4.6 model was calibrated and evaluated by Root Mean Square Error (RMSE), Index of agreement (IA) and coefficient of determination (R2). Therefore, RMSE, IA and R2 revealed a very nice agreement with observed data's set. The Results indicate that food barley yield decreases on average by 22\%, 24\% in 2030s $R C P 4.5$ and RCP8.5 respectively. Similarly yield decreases on average by RCP4.5 (25\%) and RCP8.5 (19\%) in 2050s relative to the baseline (1980-2009) due to climate change. Early sowing should be considered as an adaptation strategy for food barley under future climate.
\end{abstract}

Keywords: DSSAT model, Climate change, sowing date, food barley, GCM

\section{INTRODUCTION}

Climate change is one of the current issues that severely impact all climate sensitive sectors like agriculture. The manifestation of climate change such as rising temperatures, increasingly erratic rainfall, and more frequent and severe floods and droughts have grave consequences on the livelihood security of smallholder farming communities, making them more vulnerable. Agriculture plays a great role in the livelihood of rural communities in many African countries. Most such countries are, however, predicted to be among the globe's most vulnerable to climatic changes (Schlenker and Lobell, 2010; Samson et al., 2011; Morand et al., 2012). Muller et al. (2011) noted that the negative consequences of climate change are anticipated overall for Africa where over $95 \%$ of the farmers subsist on rain-fedagriculture. In Ethiopia, agriculture is the dominant sector contributing around $50 \%$ of the Gross Domestic Product (GDP) and 85\% of total employment and livelihoods. It is also the major source of food for the population and, hence, the prime contributor to food security (CEEPA, 2006). Climate Resilient Green Economy (CRGE, 2011) noted that climate change has the potential to hold back economic progress, or reverse the gains made in Ethiopia's development and could exacerbate social and economic problems. It is heavily dependent on rainfall, with irrigation accounting for less than $1 \%$ of the country's total cultivated land. Crop production is dominated by small scale subsistence farmers (about 8 million households) who practice more traditional farming, accounting for $95 \%$ of the total area under crop and more than $90 \%$ of the total agricultural output (CSA, 2011). Vulnerable agricultural systems are most prevalent in arid, semi-arid, and dry subhumid regions of the developing world, home to half of the world's currently malnourished 
Modeling Climate Change and its Impacts on Food Barley (HorduemvulgareL.) Production using Different Climate Change Scenariosin Lemubilbilo District, Oromia Regional State, Ethiopia

populations (Jon, 2009). The aim of this study was to investigate the influence of climate change on food barley production, which could be used for future adaptation responses.

\section{MATERIALS AND MethodS}

\subsection{The Study Area}

The study was conducted in Lemu Bilbilo District, located in Arsi Administrative Zone, Oromia Regional State of Ethiopia (Fig 1).The district is bordering Munesa in the west, DigaluTijo in the north, Shirka in the north east, and Bale zone in the south (mainly Adaba district) at 60 59'-8049'N and 38041'- 400 44'E. The district has three different geographical zones: 80\% high land, $17 \%$ midland and $3 \%$ low land, mainly characterized by crop-livestock mixed farming system.

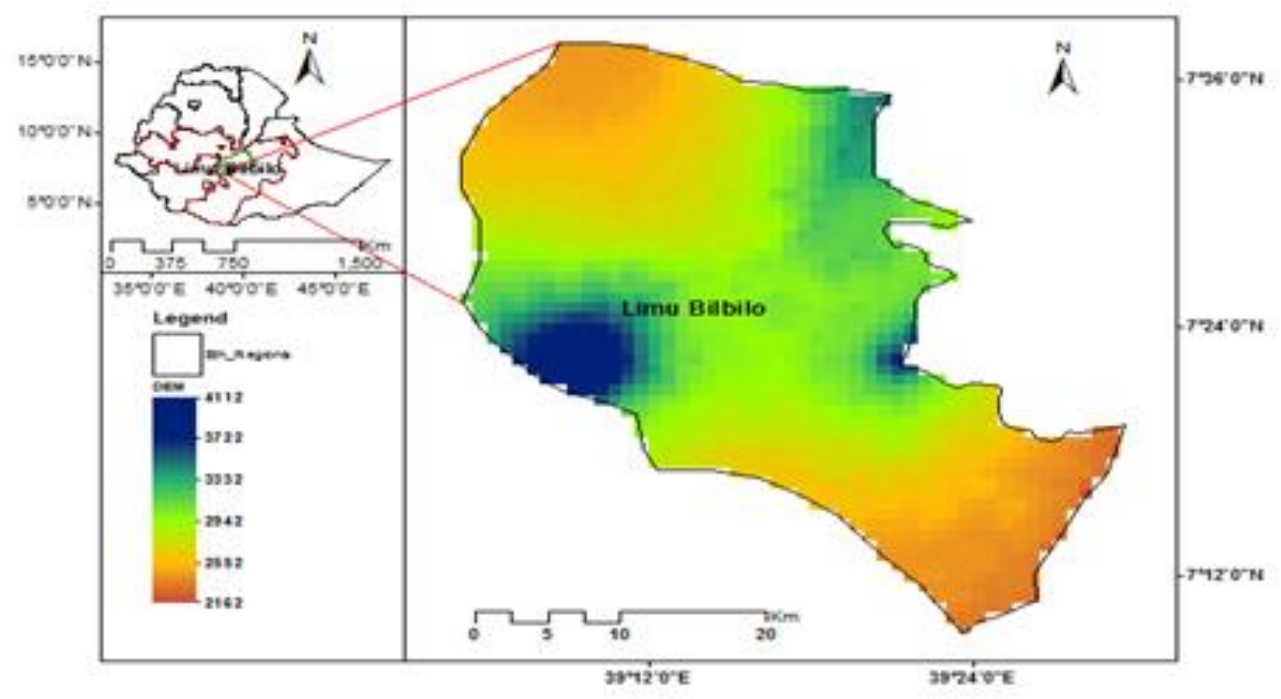

Figure1. Map of the Study Area

\subsection{Climate Change Scenarios}

Daily measured weather data for the present climate, hereafter referred to as baseline, was obtained from the National Meteorological Agency of Ethiopia (http://www.ethiomet.gov.et) for the period 1980-2009. Climate change scenarios for near-term (2010-2039) and mid-century (2040-2069) periods referred to as "2030 and 2050s" were generated using five GCMs: ACCESS1-0; CCSM4; CSIRO Mk 3.6.0; Had GEM2-ES and MIROC5from 20 GCMs obtained from Coupled Model Inter comparison (Moss et al. 2010).Project Phase 5(CMIP5) for two Representative Concentration Pathways (RCPs): RCP 4.5 and RCP 8.5 by using Ag MIP version 1.0 Climate Scenario generation tools with R software.

The GCMs were selected based on the contrasting shifts they projected with respect to temperature (T) and precipitation (P). To make the selection, we examined the projections of a range of GCMs for various emissions scenarios jointly by plotting their projected changes in $\mathrm{T}$ and $\mathrm{P}$ and chose those that best represented the window of changes, i.e. the driest, wettest, hottest and coolest scenarios. We used two of the four RCPs: RCP4.5 (a relatively modest increase in greenhouse gas concentrations) and RCP8.5 (a rapid increase in greenhouse gas concentrations). RCP4.5 refers to a path way in which the radioactive forcing of greenhouse gases reaches $4.5 \mathrm{~W} / \mathrm{m}^{2}$ in the year 2100relative to pre-industrial levels, while RCP8.5 describes a pathway in which radioactive forcing reaches $8.5 \mathrm{~W} / \mathrm{m}^{2}$ in the year 2100, relative to the pre-industrial levels (Van Vuuren et al. 2011).

The CO2 concentration for the RCP4.5 and RCP8.5 were 499 and 571 ppm by the 2050s, respectively, whereas the baseline $\mathrm{CO} 2$ concentration used in this study was $360 \mathrm{ppm}$. Climate scenarios were generated by changing the baseline climate data based on outputs from the GCMs/RCPs using the "Delta method" (Wilby et al. 2004). With the delta method, changes in rainfall are created by multiplying the rainfall scenario change factors with the baseline daily values, while changes in minimum and maximum daily temperature are obtained by adding the temperature change factors to the baseline values (Ruane et al. 2013). 


\subsection{Crop Simulation Models}

This study has focused particularly on food barley, HB 1307 developed by Holetta Agricultural Research Center (HARC) from a cross between a landrace line and exotic germplasm (Awra gebs-1 x IBON93/91) and released in 2006 for mid and high altitude areas. In this study, we used the CERES-Barley model embedded in Decision Support Systems for Agro technology Transfer (DSSAT, v4.5). This models was chosen because their well accepted and widely used in the crop modeling community toassess the impacts of climate change and evaluate various adaptation options (Tubiello and Ewert2002). In addition, they have been tested and used in the environments of Sub-Saharan Africa including Ethiopia (e.g. Jones and Thornton 2003 for DSSAT. DSSAT are designed to simulate crop growth as a function of crop features and management, weather conditions and soil characteristics. To account for the effects of elevated $\mathrm{CO} 2$ on crop growth and yield, simulations were carried out by keeping the $\mathrm{CO} 2$ concentration at the current level for the baseline period and by changing the $\mathrm{CO} 2$ concentrations for each climate change scenario to their corresponding level.

\subsubsection{DSSAT Crop Model Calibration}

The model calibration was assessed by comparing observed phonological growth and simulated days to flower, days to maturity and yield data of food barley collected during 2007, 2008,2009,2010,2011 and 2013 food barley production which available in the Annual Reports of the KARC on food barley were used for calibration. To calibrate cultivars, the typical genetic coefficients of the cultivar IB0030 Maris Badger CSM type found in the model were used for HB1307 variety.

\subsubsection{Crop Model Evaluation}

Site-specific evaluation of model performance is a precondition for using models for other locations than they were developed (Jones et al., 2001; Van Ittersumet al., 2003). The main objective of model evaluation was to adapt the model parameters to local conditions (e.g. soil types and weather conditions) to gain a good overall agreement between simulated and observed values. The data sets 2012, 2014 and 2015 were used for model evaluation.

Performance of the models was evaluated comparing the deviation between observed and simulated values. Statistical indicators, i.e. the root mean square error (RMSE), index of agreement (d) (Willmott, 1981) and coefficient of determination (R2) were used, as in other studies (e.g. Rötteret al., 2012) for evaluating the performance of DSSAT as presented in Eq 1 and 2.

$$
\mathrm{RMSE}=\sqrt{\frac{1}{\mathrm{n}} \sum_{\mathrm{n}=1}^{\mathrm{n}}\left(\mathrm{p}_{\mathrm{i}}-\mathrm{o}_{\mathrm{i}}\right)^{2}}
$$

Where $\mathrm{n}=$ number of observations, $\mathrm{Pi}=$ predicted value for the ith measurement and $\mathrm{Oi}=$ observed value for the ith measurement. Thus, lower value indicates good fit of the model.

$$
\mathrm{d}=1-\frac{\sum_{i=1}^{n}\left(P_{i}-\sigma_{i}\right)^{2}}{\sum_{i=1}^{n}\left(\left|P_{i}-P_{m}\right|+\left|\sigma_{i}-\sigma_{m}\right|\right)^{2}}
$$

The index of agreement or $\mathrm{d}$-statistic was calculated as $(0 \leq \mathrm{d} \leq 1)$. The more $\mathrm{d}$-statistic values close to unity are regarded as best agreement between the predicted and observed data (Musongaleliet al., 2014). When $\mathrm{d}=1$ indicates excellent. Where $\mathrm{n}$ : number of observations; Oiand $\mathrm{Pi}$ are observed and are predicted values, $\mathrm{Pm}$ and $\mathrm{Om}$ is the mean values of $\mathrm{Pi}$ and $\mathrm{Oi}$, respectively.

The coefficient of determination $\mathrm{R} 2$ for a linear regression model with one independent variable is:

$\mathrm{R} 2=\{(1 / \mathrm{N}) * \Sigma[(\mathrm{xo}-\mathrm{xs}) *(\mathrm{yo}-\mathrm{ys})] /(\sigma \mathrm{o} * \sigma \mathrm{s})\} 2$

Where $\mathrm{N}$ is the number of observations used to fit the model, $\sum$ is the summation symbol, $\mathrm{xo}$ is the $\mathrm{x}$ value for observed, $\mathrm{xm}$ is the mean $\mathrm{x}$ value, ysis the $\mathrm{y}$ value simulated $\mathrm{s}$, ymis the mean simulated value, $\sigma 0$ is standard deviation of xo and $\sigma y$ is the standard deviation of ys. 
Modeling Climate Change and its Impacts on Food Barley (HorduemvulgareL.) Production using Different Climate Change Scenariosin Lemubilbilo District, Oromia Regional State, Ethiopia

Yield gap analysis involves quantifying the differences between simulated potential yield and baseline levels and identifying those factors responsible for the yield differences could be easy (Belay, 2014). Baseline yields were used as the references for calculating yield gaps in the upcoming periods. Besides, the yield percentage change was calculated using the formula:

$$
\mathrm{Y}=\frac{\mathrm{Ys}-\mathrm{Yb}}{\mathrm{Yb}} * 100
$$

Where $\Delta \mathrm{Y}=$ change of yield, $\mathrm{Ys}=$ simulated yield, $\mathrm{Yb}=$ baseline yield for Impact.

\subsubsection{Adaptation Measures Under Climate Changed Future Dates}

According to NAPA (2007) potential adaptation measures include adjustments in management practices and planting date. For this particularly, study, June $25^{\text {th }}$, July $5^{\text {th }}$ and July $15^{\text {th }}$ were used as a planting window for HB1307 varieties under RCP4.5 and RCP8.5 for all time slices.

Here, it has to be noticed that first decade of July $5^{\text {th }}$ is determined to be the normal planting window. Whereas, the decadal ranges of time interval (10days before and after) the normal planting window (early June 25 and late July 15) were also considered and inter into the model CROPSIM-CERES to achieve the simulated yields.

\section{RESUltS}

\subsection{Projected Changes in Rainfall and Temperature}

The results of five GCM shows that Simulated mean annual rainfall were substantially affected by time period, RCP and type of GCM used. The highest mean annual rainfall was simulated during the midterm (2050) period under RCP8.5 with the GCM CSIRO Mk 3.6.0 (+6.49\%), whereas the lowest mean annual rainfall was simulated during the mid-term period under RCP4.5 with the GCM CSIRO Mk 3.6.0 (-6.77\%) (Table1). The ACCESS1-0 climate model has projected rainfall to increase by $0.03 \%$ under RCP4.5 in the near term. In the midterm, GCM ACCESS1-0 showed a reduction of rainfall by $2.93 \%$ under RCP4.5. Similarly, GCM CCSM4 and MIROC5 climate models predicted rainfall to increase by $1.37 \%$ and $0.85 \%$ under RCP8.5 in the near term, respectively. Even though the magnitude of the change is small, precipitation was projected to increase in the mid-term by all GCM, under RCP8.5 for the study area (Table 1). Although the annual rainfall results did not reveal a strong increasing or decreasing trend, we expect more rainfall variability in the future with medium confident level.

Table1. Projected near term (2030) and midterm (2050) changes of rainfall (\%) compared to the baseline across the five GCMs by RCP and time period

\begin{tabular}{|l|l|l|l|l|c|}
\hline & \multicolumn{5}{|c|}{ Global Climate Model (GCM) } \\
\hline RCP and period & $\begin{array}{l}\text { ACCESS1- } \\
\text { (A) }\end{array}$ & CCSM4(E) & $\begin{array}{l}\text { CSIROMk- } \\
3.6 .0(\mathrm{G})\end{array}$ & HadGEM2-ES(K) & MIROC5(O) \\
\hline Baseline & 978.9 & & & & \\
\hline NT4.5 & 0.03 & -0.97 & -3.96 & -2.40 & -0.69 \\
\hline NT8.5 & -1.98 & 1.37 & -1.91 & -0.15 & 0.85 \\
\hline MT4.5 & -2.93 & 3.81 & -6.77 & -1.06 & -0.44 \\
\hline MT8.5 & 2.15 & 5.56 & 6.49 & 0.07 & 2.14 \\
\hline
\end{tabular}

Where, RCP, Representative Concentration Pathway; NT, near term, MT, midterm; 4.5 and 8.5 are RCP4.5 and RCP8.5.

The baseline average annual minimum temperature is $8.1^{\circ} \mathrm{C}$ and maximum temperature is $20.0^{\circ} \mathrm{C}$ with mean annual temperature of $14.0^{\circ} \mathrm{C}$. The result of all GCM in near-term shows the average annual minimum temperature is expected to increase by 0.6 to $1.6{ }^{\circ} \mathrm{C}$ and the maximum temperature by 0.8 to $1.5^{\circ} \mathrm{C}$.

As a result, the mean annual temperature is expected to increase by 0.7 to $1.5{ }^{\circ} \mathrm{C}$ under RCP4.5 and RCP8.5. In midterm the average annual minimum temperature is expected to increase by 1.1 to $3.5^{\circ} \mathrm{C}$ and the maximum temperature by 1.3 to $3.2^{\circ} \mathrm{C}$ with RCP4.5 and RCP 8.5 respectively. As a result, the mean annual temperature is expected to increase by 1.2 to $3.3^{\circ} \mathrm{C}$.

The highest maximum and minimum temperatures were simulated during the mid- term period under RCP8.5 with GCM HadGEM2-ES 3.2 and $3.5^{\circ} \mathrm{c}$ respectively, whereas the lowest temperatures were simulated during the near term under RCP4.5 with GCM CCSM4.Both maximum and minimum 
Modeling Climate Change and its Impacts on Food Barley (HorduemvulgareL.) Production using Different Climate Change Scenariosin Lemubilbilo District, Oromia Regional State, Ethiopia

temperatures in RCP 4.5 and RCP 8.5 will increase during near century and midcentury compared to baseline as predicted by five GCM.

\subsection{Impact Assessment}

\subsubsection{DSSAT Model Calibration for Food Barely Production}

The specific crop model CROPSIM-CERES-Barley embedded in the DSSAT model was able to simulate most of the crop parameters with a reasonable accuracy. However, there were over and underestimation of certain parameters for certain years indicated in Fig 2.The variation in observed and simulated days to flowering, days to maturity and yield were able to be explained by coefficient of determination $\left(\mathrm{R}^{2}\right)$ values $0.72,0.89$ and 0.85 respectively (Fig 2). The Root Mean Square Error (RMSE ) values observed verses simulated days to flowering, days to maturity and yield of food barley were 1.95, 2.34 and $219.48 \mathrm{~kg} / \mathrm{ha}$, respectively. Likewise, the d-statistics values obtained were 0.98 for days to flower, 0.99 for days to maturity and 0.98 for yield, indicating good relationships of the observed with simulated values.
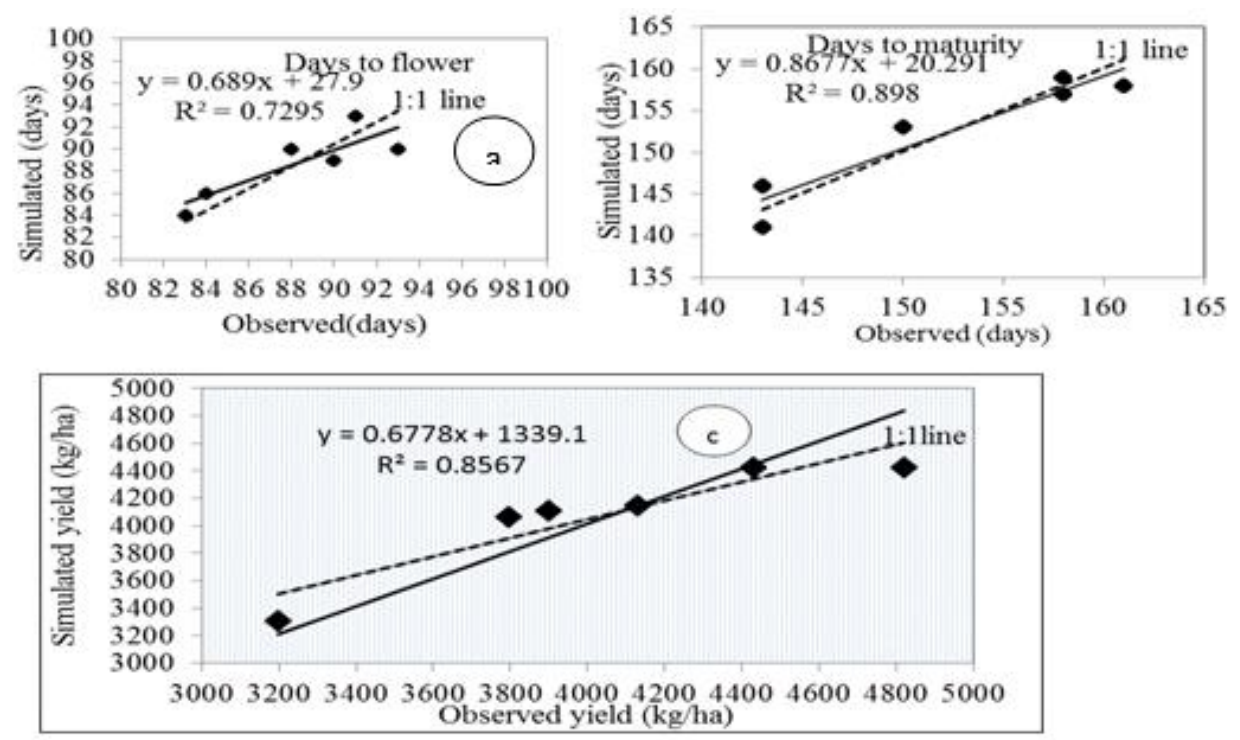

Figure2. Observed and simulated results for (a) Days to flowering, (b) Days to physiological Maturity and (c) Yield harvest for HB1307 variety

\subsubsection{Model Validation}

The model underestimated the days to flower in year 2012 and 2015. Similarly, the model has underestimated the days to maturity by $1.36 \%$ and $1.33 \%$ in the year 2012 and 2015 , respectively. The coefficient of determination analysis $\left(\mathrm{R}^{2}\right)$ between the simulated and observed value for days to flowering, days to maturity and yield $0.69,0.75$ and 0.91 , respectively. Moreover, there was a good agreement between simulated and observed values of d-statistics (agreement index) days to flowering, days to maturity and yield 0.98, 0.98 and 0.98 respectively. Likewise Root Mean Square Error (RMSE ) values from comparison of phenological parameters of Food barley simulated verses observed were $2.08,2.38$ and $121.24 \mathrm{~kg} / \mathrm{ha}$, respectively.

Table2. Comparison of simulated and observed days to flowering, maturity and grain yield of barley varieties during model validation

\begin{tabular}{|l|l|l|l|l|l|l|}
\hline & Days to flowering & \multicolumn{2}{l|}{ Days to maturity } & Yield (kg/ha) \\
\hline Year & Obs & Sim & Obs & Sim & Obs & Sim \\
\hline 2012 & 95 & 92 & 146 & 144 & 3339 & 3413 \\
\hline 2014 & 90 & 90 & 150 & 153 & 4813 & 4520 \\
\hline 2015 & 90 & 88 & 150 & 148 & 3980 & 4190 \\
\hline$R^{2}$ & 0.75 & \multicolumn{2}{|c|}{0.69} & \multicolumn{2}{c|}{0.91} \\
\hline RMSE & 2.08 & \multicolumn{2}{|c|}{2.38} & \multicolumn{2}{c|}{121.24} \\
\hline d-Stat & \multicolumn{2}{|l|}{0.98} & 0.98 & \\
\hline
\end{tabular}

Obs: observed, Sim: simulated, RMSE: root mean square of error, $d$ : $d$-statistics (index of agreement) 
Modeling Climate Change and its Impacts on Food Barley (HorduemvulgareL.) Production using Different Climate Change Scenariosin Lemubilbilo District, Oromia Regional State, Ethiopia

\subsubsection{Projections of Food Barley Yields}

The result depicted that there will be a decrease in the yield of food barley varieties in the area in the upcoming periods. The projected future climate change has a negative impact on HB1307yield in Lemu Bilbilo area in both scenarios by 2030s and 2050s periods. The change in food barley yields using DSSAT reveals consistency with the five GCMs where $20.3 \%-24.5 \%, 16 \%-34 \%$ decline in food barley yields in near-term, compared to baseline in RCP4.5 and RCP8.5 respectively.Similarly, in the midterm, with five GCM where 13.8\%-33\%, 5.8\%-33\% under RCP4.5 and RCP8.5 has shown reduction in food barley yield respectively (Table 3 ).

The highest food barley yield reduction was simulated for the near-term period under RCP8.5 with GCM CSIRO Mk 3.6.0 whereas the lowest yield reduction were simulated during the midterm under RCP8.5 (Tables 3) with GCM MIROC5 was applied. Comparing the two scenarios, the results in Table 3 revealed that RCP 8.5 has resulted in reducing yield of HB1307than the RCP 4.5 scenario; meaning that the variety have favorable condition under the RCP 4.5 scenarios than RCP 8.5 scenarios in near-term periods. Future food barley yield will generally decreased with time period and RCP across all GCMs. This result is in line with Parry et al. (2003) who showed that the SRES scenarios result in crop yield decreases in developing countries with significance in Africa.

Table3. Percent yield mean changes (\%) in food barley yield from the baseline and for five selected GCMs and two Representative Concentration Pathways (RCPs) 4.5 and 8.5

\begin{tabular}{|l|l|l|l|l|}
\hline \multirow{2}{*}{ GCMs } & NEAR-TERM & MID-TERM & \\
\cline { 2 - 5 } & RCP4.5 & RCP8.5 & RCP4.5 & RCP8.5 \\
\hline ACCESS1-0 & -21.7 & -21.5 & -31.2 & -33.0 \\
\hline CCSM4 & -24.5 & -16.1 & -17.2 & -13.4 \\
\hline CSIRO Mk 3.6.0 & -20.3 & -34.4 & -32.9 & -13.2 \\
\hline HadGEM2-ES & -21.6 & -21.9 & -29.9 & -31.7 \\
\hline MIROC5 & -22.9 & -26.8 & -13.8 & -5.8 \\
\hline Mean & -22.2 & -24.1 & -25.0 & -19.4 \\
\hline Baseline yield(kg/ha) & 2614 & & & \\
\hline
\end{tabular}

\subsubsection{Planting Date Options Against the Impact of Climate Change on Food Barley Production}

In all periods and both RCPs, yield will likely has decrease between 21.7 and $33.0 \%$ in the normal sowing date, early sowing date 9.4 and $23.7 \%$ and the late sowing date 29.4 and 40.1 by the ACCESS1-0 climate model (Table $4 \& 5$ ). However, in the late sowing date, yield will reduce in the near-term $(-39.1 \%)$ and midterm $(-40.1 \%)$ under RCP4.5 and RCP8.5 respectively.

Generally, the use of late sowing might experience more adverse impacts of climate change as rainfall ceases during the critical growth stages of the crop. In near and midterm periods and all sowing dates (normal, early and late) higher yield decline was projected under RCP8.5 compared to RCP4.5. In the normal sowing date, yield has decreased between the range of $21.6 \%$ and $31.7 \%$ using the HadGEM2-ES model (Table 4 and 5). In the late sowing date, the highest yield reduction was projected in the midterm RCP8.5 (-44.7\%) using the CSIRO Mk 3.6.0 climate model. Changing in planting dates is least-cost of adaptation strategy that should be emphasized for farmers who couldn't cope up with the challenges of climate change by introducing other technologies.

Table4. Percent yield changes (\%) simulated using DSSAT model for three sowing dates, two time periods with RCP4.5 based on five GCMs as compared to the baseline

\begin{tabular}{|l|l|l|l|l|l|l|l|}
\hline \multicolumn{7}{|l|}{ Global Climate Model(GCM) } \\
\hline Time Period & Sowing date & A & E & G & K & O & Mean \\
\hline \multirow{4}{*}{ Near-term } & Early & -17.3 & -8.1 & -12.8 & -5.4 & -8.7 & -10.5 \\
\cline { 2 - 8 } & Normal & -21.7 & -24.5 & -20.3 & -21.6 & -22.9 & -22.2 \\
\cline { 2 - 8 } & Late & -31.9 & -31.2 & 31.7 & -30.1 & -32.3 & -32.7 \\
\hline \multirow{3}{*}{ Mid-term } & Early & -15.4 & -10.1 & -21.7 & -18.0 & -5.3 & -14.1 \\
\cline { 2 - 8 } & Normal & -31.2 & -17.2 & -32.9 & -29.9 & -13.8 & -36.6 \\
\cline { 2 - 8 } & Late & -39.1 & -30.8 & -41.5 & -40.3 & -31.1 & -25.0 \\
\hline
\end{tabular}

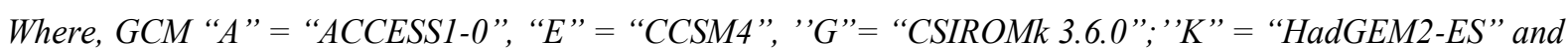
"O"="MIROC5”, RCP, Representative Concentration Pathway 
Modeling Climate Change and its Impacts on Food Barley (HorduemvulgareL.) Production using Different Climate Change Scenariosin Lemubilbilo District, Oromia Regional State, Ethiopia

Table5. Percent yield changes (\%) simulated using DSSAT model for three sowing dates, two time periods with RCP8.5 based on five GCMs as compared to the baseline

\begin{tabular}{|c|c|c|c|c|c|c|c|}
\hline & \multicolumn{7}{|c|}{ Global Climate Model (GCM) } \\
\hline Time Period & Sowing date & $\mathrm{A}$ & $\mathrm{E}$ & $\mathrm{G}$ & $\mathrm{K}$ & $\mathrm{O}$ & Mean \\
\hline \multirow{3}{*}{ Near-term } & Early & -9.4 & -7.5 & -11.0 & -13.1 & -6.5 & -14.1 \\
\hline & Normal & -21.7 & -16.1 & -34.4 & -21.9 & -26.8 & -25.0 \\
\hline & Late & -29.4 & -26.9 & -35.1 & -36.7 & -35.7 & -36.6 \\
\hline \multirow{3}{*}{ Mid-term } & Early & -23.7 & -4.7 & -27.6 & -22.5 & 2.0 & -15.3 \\
\hline & Normal & -33.0 & -13.4 & -13.2 & -31.7 & -5.8 & -19.4 \\
\hline & Late & -40.1 & -27.4 & -44.7 & -40.7 & -33.0 & -37.2 \\
\hline
\end{tabular}

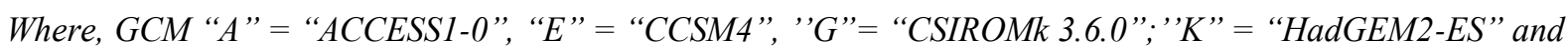
"O”="MIROC5”, RCP, Representative Concentration Pathway

\section{CONCLUSION}

The Result shows that the maximum temperature over the area had increased by and $0.076{ }^{\circ} \mathrm{C}$ per year. Likewise, the minimum temperature was increased by $0.049{ }^{\circ} \mathrm{C}$ per year. The climate modeling results for the near-term suggest that the average annual minimum temperature is expected to increase by 0.6 to $1.6{ }^{\circ} \mathrm{C}$ and the maximum temperature by 0.8 to $1.5^{\circ} \mathrm{C}$ under RCP4.5 and RCP8.5. As a result, the mean annual temperature is expected to increase by 0.7 to $1.5{ }^{\circ} \mathrm{C}$ under RCP4.5 and RCP8.5. In midterm the average annual minimum temperature is expected to increase by 1.1 to $3.5^{\circ} \mathrm{C}$ and the maximum temperature by 1.3 to $3.2^{\circ} \mathrm{C}$ with RCP4.5 and RCP8.5.As a result, the mean annual temperature is expected to increase by 1.2 to $3.3{ }^{\circ} \mathrm{C}$. Although the annual rainfall results did not reveal a strong increasing or decreasing trend, we expect more rainfall variability in the future. Under Climate change, food barley yields are expected to decrease in the future. The result of this study predicts that food barley yield declines would ranging from $-20.3 \%$ to $-24.5 \%,-16.1 \%$ to- $34.4 \%$ in the 2030s under RCP4.5 and RCP8.5 respectively. Similarly in the 2050s the declines would range $17.2 \%$ to $-32.9 \%,-5.8 \%$ to $-33 \%$ under RCP4.5 and RCP8.5 respectively. Hence, to reduce the negative impacts of climate change, early planting is one of the adaptation options to consider for food barley production in LemuBilbilo.

\section{ACKNOWLEDGEMENT}

The authors declare that there is no conflict of interests regarding the publication of this paper. This work has been carried out with support from the Hawasa University (HU). I would like to thank Hawasa University for granting me the research fund. Likewise, special thanks to National Meteorology Agency of Ethiopia (NMA) support me to complete the work, and for providing longterm climatic data free charge.

\section{REFERENCES}

[1] Belay, T. K. 2014. Climate variability and change in Ethiopia: Exploring impacts and adaptation options for cereal production. Wit Graduate School of Production Ecology and Resource Conservation. PhD thesis. Wageningen University.p163.

[2] CEEPA. 2006. Climate change and African agriculture. University of Pretoria, South Africa. Policy note No. 25

[3] CRGE (Climate Resilient Green Economy). 2011. Ethiopia's Vision for Resilient Green Economy. Federal Democratic Republic of Ethiopia.

[4] CSA (Central Statistical Agency). 2011. Area and Production of Crops. Statistical Bulletin. Central Statistical Agency of Ethiopia.

[5] Jon, P. 2009. Agricultural development under a changing climate: Opportunities and challenges for adaptation. Joint Discussion Paper. Agriculture and rural development and environment departments. The International Bank for Reconstruction and Development/the World Bank. Washington D.C., USA.

[6] Jones PG, Thornton PK (2003) the potential impacts of climate change on maize production in Africa and Latin America in 2055. Glob Environ Chang 13(1):51-59

[7] Jones, J., Keating, B., Porter, C., 2001. Approaches to modular model development. Agricultural Systems 70, 421-443.

[8] Morand, P., Kodio, A., Andrew, N., Sinaba, F., Lemoalle, J. and Bene , C. 2012. Vulnerability and adaptation of African rural populations to hydro-climate change: Experience from fishing communities in the Inner Niger Delta (Mali). Climatic Change 115(3-4): 463-483. 
Modeling Climate Change and its Impacts on Food Barley (HorduemvulgareL.) Production using Different Climate Change Scenariosin Lemubilbilo District, Oromia Regional State, Ethiopia

[9] Moss RH et al (2010) the next generation of scenarios for climate change research and assessment. Nature 463(7282):747-756

[10] Muller, C., Cramer, W., Hare, W. L. and LotzeCampen, H. 2011. Climate change risks for African agriculture. Proceedings of the National Academy of Sciences of the United States of America 108(11):4313-4315.

[11] Musongaleli, B., Filbert, R., Siza, D. and Tumbo, N. K. 2014. Sorghum yield response to changing climatic conditions in semi-arid central Tanzania: Evaluating crop simulation model applicability. Agricultural Sciences, 2014, 5, 822-833. http://www.scirp.org/journal/as http://dx.doi.org/10.4236/as.2014.510087. Accessed on 11 February 2017.

[12] NAPA. 2007. Climate change National Adaptation Program of Action (NAPA) of Ethiopia. Ministry of Water Resources, Addis Ababa.

[13] Parry, M.L., Rosenzweig, C., Iglesias, A., Livermore, M. and Fischer, G. 2003. Effects of climate change on global food production under SRES emissions and socio-economic scenarios. Global Environmental Change. p114.

[14] Rötter, R.P., Palosuo, T., Kersebaum, K.C., Angulo, C., Bindi, M., Ewert, F., Ferrise, R., Hlavinka, P., Moriondo, M., Nendel, C., 2012. Simulation of spring barley yield in different climatic zones of Northern and Central Europe: A comparison of nine crop models. Field Crops Research 133, 23-36.

[15] Ruane AC et al (2013) Climate change impact uncertainties for maize in Panama: farm information, climate projections, and yield sensitivities. Agric For Meteorol 170:132-145

[16] Samson, J., Berteaux, D., McGill, B.J. and Humphries, M.M. 2011. Geographic disparities and moral hazards in the predicted impacts of climate change on human populations. Global Ecology and Biogeography 20(4):532-544.

[17] Schlenker, W. and Lobell, D.B. 2010. Robust negative impacts of climate change on African agriculture. Environmental Research Letters 5(1):1-8.

[18] Tubiello FN, Ewert F (2002) Simulating the effects of elevated CO2 on crops: approaches and applications for climate change. Eur J Agron 18(1):57-74

[19] Van Ittersum, M. K., Leffelaar, P., Van Keulen, H., Kropff, M., Bastiaans, L., Goudriaan, J., 2003. On approaches and applications of the Wageningen crop models. Europian Journal of Agronomy 18, 201-234.

[20] Van Vuuren DP et al (2011) The representative concentration pathways: an overview. Clim Chang 109(12):5-31

[21] Wilby R et al (2004) Guidelines for use of climate scenarios developed from statistical downscaling methods. IPCC task group on data and scenario support for impacts and climate analysis

[22] Willmott, C.J., 1981. On the validation of models. Physical Geography 2, 184-194.

Citation: BekeleKebebe, et.al, "Modeling Climate Change and its Impacts on Food Barley (HorduemvulgareL.) Production using Different Climate Change Scenariosin Lemubilbilo District, Oromia Regional State, Ethiopia", International Journal of Research in Environmental Science (IJRES), vol. 5, no. 3, pp. 33-40, 2019. Available: DOI: http://dx.doi.org/10.20431/2454-9444.0503005

Copyright: (C) 2019 Authors. This is an open-access article distributed under the terms of the Creative Commons Attribution License, which permits unrestricted use, distribution, and reproduction in any medium, provided the original author and source are credited. 